Please refer tot he following:

Károly Jármai, Hendrik Pahlke, József Farkas

Cost savings using different post welding treatments on an I-beam subject to fatigue load

WELDING IN THE WORLD (ISSN: 0043-2288) 58: (5) pp. 691-698. (2014)

\title{
Cost savings using different post welding treatments on an I-beam subject to fatigue load
}

\section{Károly Jármai ${ }^{1}$, Hendrik Pahlke², József Farkas ${ }^{3}$,}

Doc. XIII-2499-13, XV-1442-13, recommended for publication by Commission XV "Design, analysis and fabrication of welded structures"

Károly Jármai, University of Miskolc, H-3515 Miskolc, Egyetemváros, Hungary, ${ }^{1}$ Professor, Dr.sci.techn. altjar@uni-miskolc.hu, (corresponding author)

Hendrik Pahlke, Otto-von-Guericke-Universität Magdeburg, D-39106 Magdeburg, Universitätsplatz 2, Germany, MSc. Student, within an Erasmus exchange program,

József Farkas, University of Miskolc, H-3515 Miskolc, Egyetemváros, Hungary, Professor emeritus, Dr.sci.techn.altfar@uni-miskolc.hu

\begin{abstract}
In the framework of this work research has been carried out to obtain current data on the potential of post weld treatment (PWT) since new PWT technologies appeared in the last years, and the older technologies have been improved. The economy of post-welding treatments is illustrated by means of a numerical example of a simply supported welded I-beam loaded in bending by a pair of pulsating forces. The vertical stiffeners are welded to the I-beam upper flange by double fillet welds, which cause a significant decrease of fatigue stress range. This low fatigue stress range is improved by various post-welding treatments. Based on the published experimental data, it is possible to determine the measure of the increase of the fatigue stress range as well as the required treatment time for grinding, TIG dressing, hammer peening and ultrasonic impact treatment. This article provides an overview of current PWT methods and the possible improvement in fatigue strength.

Furthermore, optimization of a welded I-beam has been conducted to reduce the fabrication cost. The data from the research in the form of increase in fatigue strength and application speed were included in this optimization. The treatment time is included into the cost function, and the improved fatigue stress range is considered in the fatigue constraint. The comparison of costs for optimum structural versions with and without treatments shows the economy of different treatment methods. This comparison helps designers to consider the applicability of PWT and the select the best available.
\end{abstract}

Keywords: minimum cost design, welded I-beams, post-welding treatments, improvement of fatigue stress range, economy of welded structures

\section{Introduction}

For welded structures, fatigue is one of the most dangerous phenomena [1]. Residual stresses caused by welding and sharp stress concentrations around the weld, which are responsible for the significant decrease of fatigue strength. The most dangerous points where fatigue cracks initiate and propagate are butt welds with partial penetration, toes and roots of the fillet weld.

Several methods have been developed and investigated in order to eliminate or decrease the danger of fatigue fracture. Post-welding treatments (PWT-s) are the most efficient methods. These methods have been tested, and a lot of experimental results show their effectiveness and reliability. 
Post weld treatment can be done in several ways; Post weld heat treatment to release residual stress, overloading, mechanical or thermal post-treatment of the weld toe. The weld toe is often the source of fatigue cracking because of the sharp transition between the weld and the plate surface and the existence of micro-cracks. The techniques presented in this paper deal with the improvement of the weld toe.

\section{Weld toe improvement methods}

Weld toe improvement methods can be classified in two groups according to their mode of functioning. One type of treatment improves the geometry of the weld toe, to reduce the stress concentration by creating a smoother transition between weld and plate surface. The other type of treatment mainly introduces compressive residual stresses and thus prevents the crack propagation.

The burr grinding and TIG-dressing techniques improve the weld toe. The shot peening, hammer peening, UIT and HiFIT techniques introduce compressive residual stresses through mechanical deformation. Furthermore, the surface is hardened, and the weld toe geometry is improved.

The success of the treatment depends on several parameters. One significant point is the yield strength of the material. The other parameters are the type of weld seam (e.g. butt or longitudinal weld), and the stress range $\mathrm{R}$. The higher the stress range, the lower the improvement [28]. For the application in the workshop, many other parameters have to be considered to assure the optimal improvement.

\subsection{Burr Grinding}

Burr grinding reduces or removes small weld flaws. Furthermore, the weld toe geometry is improved by smoothing the transition between weld and plate surface $[2,3]$.

The tool can be a fast rotating burr grinder with 15000 to 40000rpm [2]. Grinders with different diameters are needed to adapt the treatment to different weld seams.

\subsection{TIG-Dressing}

In the TIG-dressing process, the weld toe is remelted to create a smooth transition. This reduces the stress concentration. Furthermore, weld flaws such as cold laps, undercuts and inclusions are removed $[2,6]$. Manual TIG-dressing can be done with a standard TIG-welding machine without filler material.

\subsection{Shot-Peening}

In the shot peening process, small metal shots are propelled against the plate surface with a high velocity. When the shots hit the surface, it causes yielding of the material [4] and thus the introduction of compressive residual stress, a hardening of the surface and an improvement of the weld toe geometry [13].

\subsection{Hammer Peening}

The weld toe is hammered repeatedly with an electrical or a pneumatic hammer [2]. The head is vibrating with a frequency of $20-100 \mathrm{~Hz}$ [9]. Compressive residual stresses are introduced and the weld toe geometry is improved [4].

\subsection{Needle Peening}

Needle peening is a variation of hammer peening. Instead of a single hammer head the tool tip consists of several hardened steel pins. The mode of functioning, which leads to the improvement in fatigue strength, is the same one as for the hammer peening. Through the yielding material at the weld toe, compressive residual stresses are introduced and the weld toe geometry is improved.

The tool can be a standard or a modified needle gun [2].

\subsection{UIT}

"Ultrasonic Impact Treatment" (UIT) technique was developed in the Soviet Union, to improve the welds of submarines. The UIT device is operated by magnetostriction [3] and an ultrasonic wave of $27-55$ $\mathrm{kHz}$ is transformed to a mechanical oscillation of around $200 \mathrm{~Hz}$ and an overlain ultrasonic wave $[6,11]$. 
The tool has one or several steel pins with which the weld toe is treated. This creates compressive residual stresses and improves the weld toe geometry [6]. Furthermore, a hardening of the surface occurs [9] and the ultrasonic wave is supposed to reduce tensile residual stresses [6].

\subsection{HiFIT}

The "High Frequency Impact Treatment" (HiFIT) is an advancement of the hammer peening technique, as for the UIT a special device has been developed just for the purpose of post weld treatment. The tip of the tool usually with a diameter of $3 \mathrm{~mm}$ is vibrating with a frequency of $180-300 \mathrm{~Hz}$ [10]. The results of the treatment are similar to those of the UIT: compressive residual stresses are introduced, the surface is hardened, small weld flaws are removed [9] and the weld toe geometry is improved.

\section{Research results}

During the research, 33 papers and articles dealing with the topic of post weld treatment were examined. 31 papers contained information on the potential increase in fatigue strength, and 12 papers contained information on application speed of PWT methods. Almost all the articles dealt with treatment of steel, and only few data were available on aluminium, hence the focus is set on the improvement of steel structures.

The increase in fatigue strength is compared to as-welded joints, which were usually examined in the described experiments and refers to $2 * 10^{6}$ cycles. The results of the research are given in Table 1 . The data are sorted according to the material strength, and data not assigned to a steel grade are put in an extra column. In the table (hf) is relates for high frequency.

Table 1 - Possible increase in fatigue strength [\%]

\begin{tabular}{llllll}
\hline Method & $\begin{array}{l}\text { Material not } \\
\text { specified }\end{array}$ & $\leq 355 \mathrm{MPa}$ & $\begin{array}{l}>355 \mathrm{MPa} \\
<900 \mathrm{MPa}\end{array}$ & $\geq 900 \mathrm{MPa}$ & References \\
\hline Burr Grinding & $30-200$ & 30 & $30-58$ & & {$[2,4,5,18,20,30]$} \\
\hline TIG-Dressing & $30-100$ & $15-74$ & $27-74$ & $60-90$ & {$[2,4,5,6,17,18,24]$} \\
\hline Shot Peening & & 33 & $38-70$ & & {$[4,13,24]$} \\
\hline Hammer Peening & $50-200$ & 30 & $50-70$ & & {$[2,4,5,17,21,29,32(\mathrm{hf})]$} \\
\hline Needle Peening & 60 & 30 & 50 & & {$[2,14,29,32(\mathrm{hf})]$} \\
\hline UIT & $50-200$ & $44-116$ & $80-168$ & 110 & {$[4,6,8,9,11,12,15$,} \\
& & & & & $16,17,19,22,31,32(\mathrm{hf})]$ \\
\hline HiFIT & $80-100$ & $64-82$ & $83-102$ & & {$[9,10,12,15,16,32(\mathrm{hf})]$}
\end{tabular}

Table 2 shows the application speed for the post weld treatments. The application speed refers to full coverage of the weld toe, meaning that when several passes of treatment are necessary, the speed has already been divided by the number of passes.

Unfortunately, the range of the application speed is varying strongly among the different papers. The range of the increase in fatigue strength is also quite large. Therefore, some adjustment has to be made to acquire suitable values for a calculation. Also for the increase in fatigue strength values have to be selected to be used in the calculation.

The values, for which the material grades were not given, will not be considered in the calculation. To keep the calculation conservative not always the highest possible values are taken. It is not appropriate to use just the smallest values, due to the fact that the minimum values are sometimes much smaller than the maximum values.

Table 2 - Results on application speed [min/m]

\begin{tabular}{lll}
\hline Method & $\begin{array}{l}\text { Speed } \\
{[\mathrm{min} / \mathrm{m}]}\end{array}$ & References \\
\hline Burr Grinding & $6.1-60$ & {$[2,3,4,5,7,20]$} \\
\hline TIG-Dressing & $5-18.2$ & {$[2,3,5,6,7,18,23]$} \\
\hline Shot Peening & $0.3-0.6$ & {$[13]$} \\
\hline Hammer Peening & $4-20$ & {$[2,5,7,21]$} \\
\hline Needle Peening & 2.5 & {$[2]$} \\
\hline
\end{tabular}




\begin{tabular}{lll}
\hline UIT & $1.1-15.5$ & {$[3,17,22,25]$} \\
\hline HiFIT & $3.3-5.5$ & {$[9,10,16]$} \\
\hline
\end{tabular}

The general trend shows that the higher the steel grade, the bigger increase in fatigue strength. Some papers stated that this is only valid for the residual stress methods $[4,5]$ nevertheless the numbers show this trend even for burr grinding and TIG-dressing. Therefore, the highest values considered will be assigned to the highest steel grade the lowest to the lowest grade. When no data are given, the value for the middle strength steel is assigned to the highest steel grade, and the middle value is interpolated.

For burr grinding and TIG-dressing the lowest value is taken to be 30\%, which is given by the IIW [2]. The maximum value of burr grinding will be $58 \%$ given by Zaczek [18]. The maximum value for TIGdressing will be only $60 \%$ because even for higher steel grades there was often only an increase of around $50-70 \%$ as can be seen in Gerster [6] and Zaczek [18]. The extreme values for shot peening come from Maddox [26] where Hasegawa et al. [13, 24] indicate values that lie in between.

For hammer peening and needle peening, the minimum values are provided by the IIW [2]. The maximum value for hammer peening is set to $80 \%$ because its effect is said to be greater than that of shot and needle peening [4]. The effect of needle peening is generally slightly less than that of hammer peening; therefore its maximum value is set to $60 \%$ [14]. For UIT, the minimum is set to 50\% according to [8] and [19]. The maximum value will be $110 \%[6,8,11]$. This is maybe a conservative estimate, but in several papers, which dealt with HiFIT and UIT treatment the maximum increase was $102 \%$. The data for HiFIT treatment are taken from $[9,12,15,16]$. These papers dealt with UIT and HiFIT together. The results of the two treatments were so similar that they even gave the same numbers for the possible improvement.

The travel speed is decreasing with increasing yield strength [2] which is valid for all the treatments methods except at TIG-dressing, where IIW [2] gave recommendations considering the application speed these ranges were applied for the following calculations. The maximum speed is given for the mild steel, and the minimum speed for the high strength steel. This was possible for burr grinding, TIG-dressing, hammer peening and needle peening. For shot peening, only one paper provided a travel speed. Hasegawa et al. [13] give a speed of $0.3-0.6 \mathrm{~min} / \mathrm{m}$.

The travel speed for HiFIT was taken from the manufacturer's brochure [10]. For the UIT treatment, a large range of possible travel speed is given in several articles. Roy et al. [25] recommend a speed of 3.3 to $16.6 \mathrm{~min} / \mathrm{m}$, whereas Martinez et al. [17] give a speed of 1.4 to $3.3 \mathrm{~min} / \mathrm{m}$, and Pederson et al. [3] give an even higher speed of 1.1 to $1.4 \mathrm{~min} / \mathrm{m}$ for high-quality weld seams only. A speed from $1.4 \mathrm{~min} / \mathrm{m}$ for mild steel and of $3.3 \mathrm{~min} / \mathrm{m}$ for higher strength steel seems appropriate.

Table 3 and Table 4 sum up the results of the data adjustment for the following optimization.

Table 3 - Increase in fatigue strength in $\%$ for the optimization

\begin{tabular}{lllll}
\hline Method & $\leq 355 \mathrm{MPa}$ & $\begin{array}{l}>355 \mathrm{MPa} \\
<900 \mathrm{MPa}\end{array}$ & $\geq 900 \mathrm{MPa}$ & Comments \\
\hline Burr Grinding & 30 & 44 & 58 & Values up to 200 \\
\hline TIG-Dressing & 30 & 45 & 60 & Values up to 100 \\
\hline Shot Peening & 33 & 51 & 70 & \\
\hline Hammer Peening & 30 & 55 & 80 & Values up to 200 \\
\hline Needle Peening & 30 & 45 & 60 & Values up to 200 \\
\hline UIT & 50 & 80 & 110 & \\
\hline HiFIT & 60 & 81 & 102 & \\
\hline
\end{tabular}

Table 4 - Application speed in $\mathrm{min} / \mathrm{m}$ for the optimization

\begin{tabular}{lllll}
\hline Method & $\leq 355 \mathrm{MPa}$ & $\begin{array}{l}>355 \mathrm{MPa} \\
<900 \mathrm{MPa}\end{array}$ & $\geq 900 \mathrm{MPa}$ & Comments \\
\hline Burr Grinding & 10 & 15 & 20 & IIW [2] \\
\hline TIG-Dressing & 6.25 & 9.4 & 12.5 & IIW [2] \\
\hline Shot Peening & 0.3 & 0.45 & 0.6 & {$[13]$} \\
\hline Hammer Peening & 10 & 15 & 20 & IIW [2] \\
\hline Needle Peening & 2.5 & 3.5 & 4.5 & IIW [2] \\
\hline UIT & 1.4 & 2.4 & 3.3 & \\
\hline
\end{tabular}




\begin{tabular}{llll}
\hline HiFIT & 3.3 & 4.4 & 5.5
\end{tabular}

We can have even more improvement if we combine PWT techniques, like burr grinding and hammer peening and others [30]. In that case, the treatment time is longer. The improvement effect of PWT techniques depends on the quality control parameter variations. For UIT, it was investigated in [32]. The welded joints can be over-treated and under-treated. We considered properly treated joints.

\section{Minimum cost design of a welded I-beam}

In the preceding article [27] the minimum cost design of a welded I-beam has been carried out with the PWT-methods burr grinding, TIG-dressing, hammer peening and UIT. In this investigation the methods shot peening, needle peening and HiFIT and current data on the PWT-methods have been added.

In the numerical example, a welded I-beam with transverse vertical stiffeners is investigated. The stiffeners are welded to the beam with double fillet welds. The beam is loaded with two fluctuating forces with the amplitude $F_{\max }$ and the minimum 0 . The bending stress is calculated with $F_{\max }$.

PWT is only used in the middle part of the beam where the stress is the highest. The stiffeners in the middle span are not welded to the tension flange of the beam. Therefore, two different types of stiffeners are used as it can be seen in Figure 1.

\subsection{The cost function}

In the previous study [27] the following cost function containing the material and costs has been used:

$$
K=K_{m}+K_{f}=k_{m} \rho V+k_{f} \sum T_{i}
$$

where $K_{m}$ is the material cost and $K_{f}$ the fabrication cost. $k_{m}$ and $k_{f}$ are the corresponding cost factors, $\rho$ is the material density, $V$ the volume of the structure and $T_{i}$ are the production times.

Eq. (1) can be written as

$$
\frac{K}{k_{m}}=\rho V+\frac{k_{f}}{k_{m}} \sum T_{i}
$$

We use the following cost factors: $k_{m}=0.5-1 \$ / \mathrm{kg}, k_{f \max }=60 \$ / \mathrm{h}=1 \$ / \mathrm{min}$, and thus the ratio of $k_{f} / k_{m}$ can be varied in a wide range of $0-2 \mathrm{~kg} / \mathrm{min} . k_{f} / k_{m}=0$ means that $K / k_{m}$ is a weight (mass) function, $k_{f} / k_{m}=2 \mathrm{~kg} / \mathrm{min}$ can be used for developed countries.

The fabrication times can be calculated as follows:

$$
\sum T_{i}=T_{1}+T_{2}+T_{3}+T_{4}
$$

Time for preparation, assembly and tacking is

$$
T_{1}=C_{1} \Theta_{d} \sqrt{\kappa \rho V}
$$

where $C_{l}=1 \mathrm{~min} / \mathrm{kg}^{0.5}, \Theta_{d}$ is a difficulty factor expressing the complexity of a structure (planar or spatial, consisting of plates or tubes etc.), $\kappa$ is the number of elements to be assembled.

Time for welding is

$$
T_{2}=\sum C_{2 i} a_{w i}^{n} L_{w i}
$$

where $C_{2 i} a_{w i}^{n}$ is given for different welding technologies and weld shapes according to COSTCOMP software [15] and [14], $a_{w}$ is the weld size, $L_{w}$ is the weld length. 

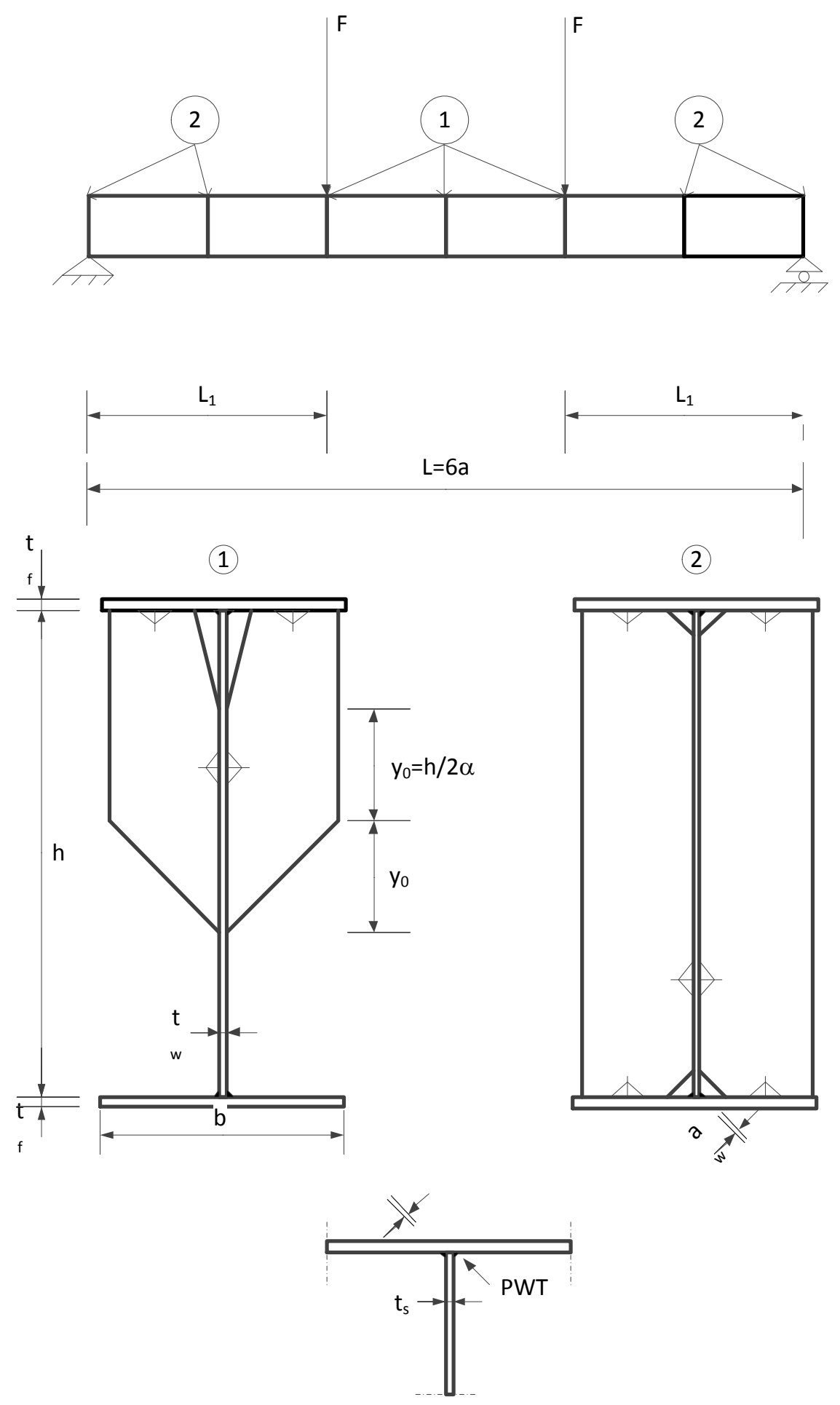

Figure 1 - Welded I-beam with vertical stiffeners. Double fillet welds with (1) and without (2) PWT

Time for additional works as deslagging, chipping and electrode changing is

Time for PWT is

$$
T_{3}=0.3 T_{2}
$$

$$
T_{4}=T_{0} L_{t}
$$

$T_{0}$ is the specific time $(\mathrm{min} / \mathrm{mm}), L_{t}$ is the treated weld length $(\mathrm{mm})$.

The final form of the cost function is 


$$
\frac{K}{k_{m}}=\rho V+\frac{k_{f}}{k_{m}}\left(\Theta_{d} \sqrt{\kappa \rho V}+1.3 \sum C_{2 i} a_{w i}^{n} L_{w i}+T_{0} L_{t}\right)
$$

\subsection{Design constraints}

The constraint on fatigue stress range can be formulated as

where

$$
\frac{F_{\max } L_{1}}{W_{x}} \leq \frac{\alpha \Delta \sigma_{C}}{\gamma_{M f}}
$$

$$
W_{x}=\frac{I_{x}}{\frac{h}{2}+\frac{t_{f}}{2}}, \quad I_{x}=\frac{h^{3} t_{w}}{12}+2 b t_{f}\left(\frac{h}{2}+\frac{t_{f}}{2}\right)^{2}
$$

According to Eurocode 3 (EC3) [34] the fatigue stress range for as welded structure is $\Delta \sigma_{C}=80 \mathrm{MPa}$, the fatigue safety factor is $\gamma_{M f}=1.25 . \alpha$ expresses the measure of improvement

$$
\alpha=\frac{\Delta \sigma_{\text {Cimproved }}}{\Delta \sigma_{\text {Caswelded }}}
$$

The constraint on local buckling of the web according to EC3 is

$$
\frac{h}{t_{w}} \leq 69 \varepsilon ; \quad \varepsilon=\sqrt{\frac{235}{\alpha \Delta \sigma_{C} / \gamma_{M f}}}
$$

Note that we calculate in the denominator of $\varepsilon$ with the maximum compressive stress instead of yield stress [17].

The constraint on local buckling of the compression flange is

$$
\frac{b}{t_{f}} \leq 28 \varepsilon
$$

\subsection{Numerical example}

Data: $F_{\max }=138 \mathrm{kN}, L=12 \mathrm{~m}, L_{l}=4 \mathrm{~m}, \Delta \sigma_{C} / \gamma_{M f}=80 / 1.25=64 \mathrm{MPa}, \varepsilon=1.916 / \sqrt{\alpha}$;

$\Theta_{d}=3$; number of stiffeners is $2 * 7=14$, thus $\kappa=3+14=17$.

The volume of the structure is

$$
V=\left(h t_{w}+2 b t_{f}\right) L+4 b h t_{S}+1.5 b h t_{S}\left(1+\frac{1}{\alpha}\right) \quad t_{s}=6 \mathrm{~mm}
$$

The second member expresses the volume of stiffeners without PWT, the third member gives the volume of stiffeners with PWT.

For longitudinal GMAW-C (gas metal arc welding with $\mathrm{CO}_{2}$ ) fillet welds of size $4 \mathrm{~mm}$, we calculate with

$$
\mathrm{C}_{2} \mathrm{a}_{\mathrm{w}}^{\mathrm{n}} \mathrm{L}_{\mathrm{w}}=0.33948 * 10^{-3} * 4^{2} * 4 \mathrm{~L}=260
$$


for transverse SMAW (shielded metal arc welding) fillet welds the following formula holds

$$
\mathrm{C}_{2} \mathrm{a}_{\mathrm{w}}^{\mathrm{n}} \mathrm{L}_{\mathrm{w}}=0.7889 * 10^{-3} * 4^{2}\left[6\left(\mathrm{~b}+\frac{2 \mathrm{~h}}{\alpha}\right)+16(\mathrm{~b}+\mathrm{h})\right]
$$

For the constrained minimization of the nonlinear cost function, the Rosenbrock Hillclimb mathematical programming method is used complementing it with an additional search for optimum rounded discrete values of unknowns. The results of computation, i.e. the unknown dimensions $h, t_{w}, b$ and $t_{f}$ as well as the minimum costs for different values of $k_{f} k_{m}$ and $\alpha$ are given in Table 6 .

To get an overview of the results Figure 2 and 3 present the cost for the different material grades and PWTmethods.

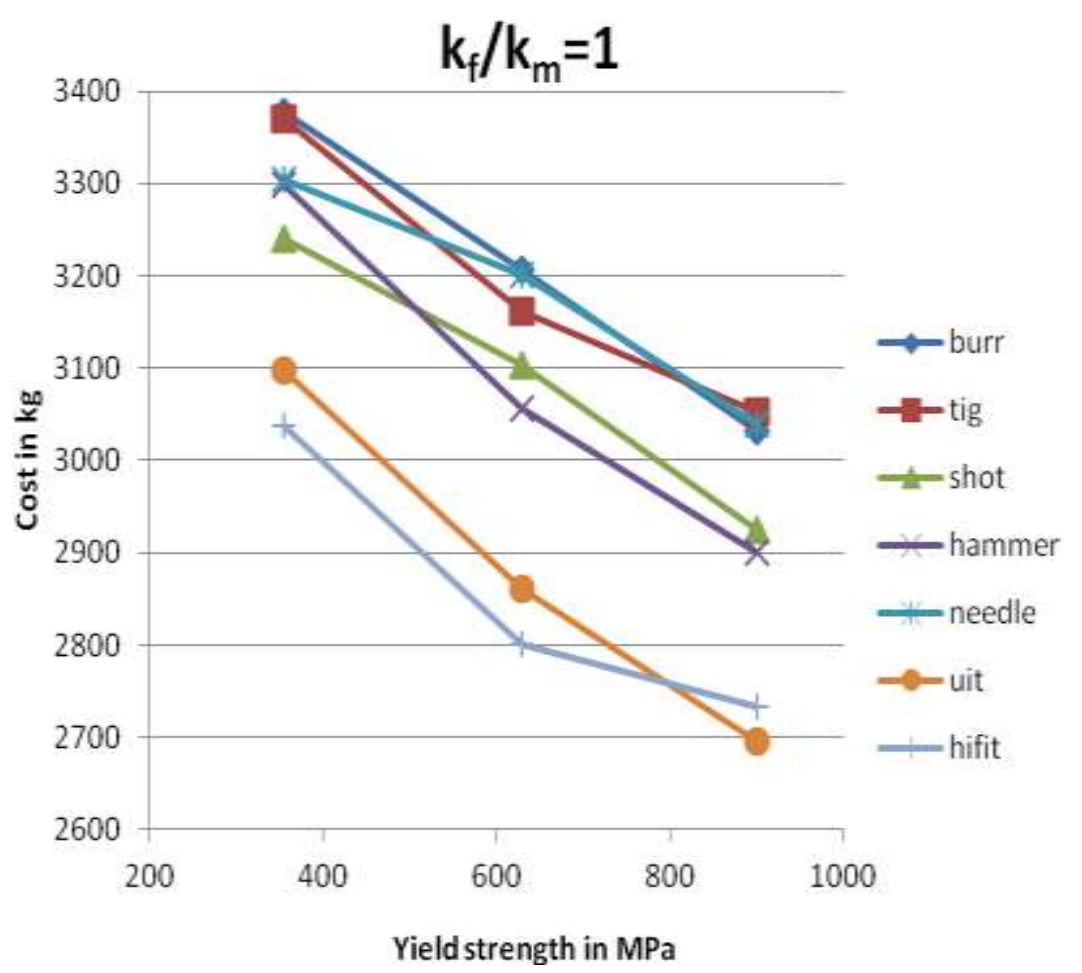

Figure 2 - The optimum costs are in the function of the yield stress for $k_{\mathrm{f}} / k_{\mathrm{m}}=1$ 


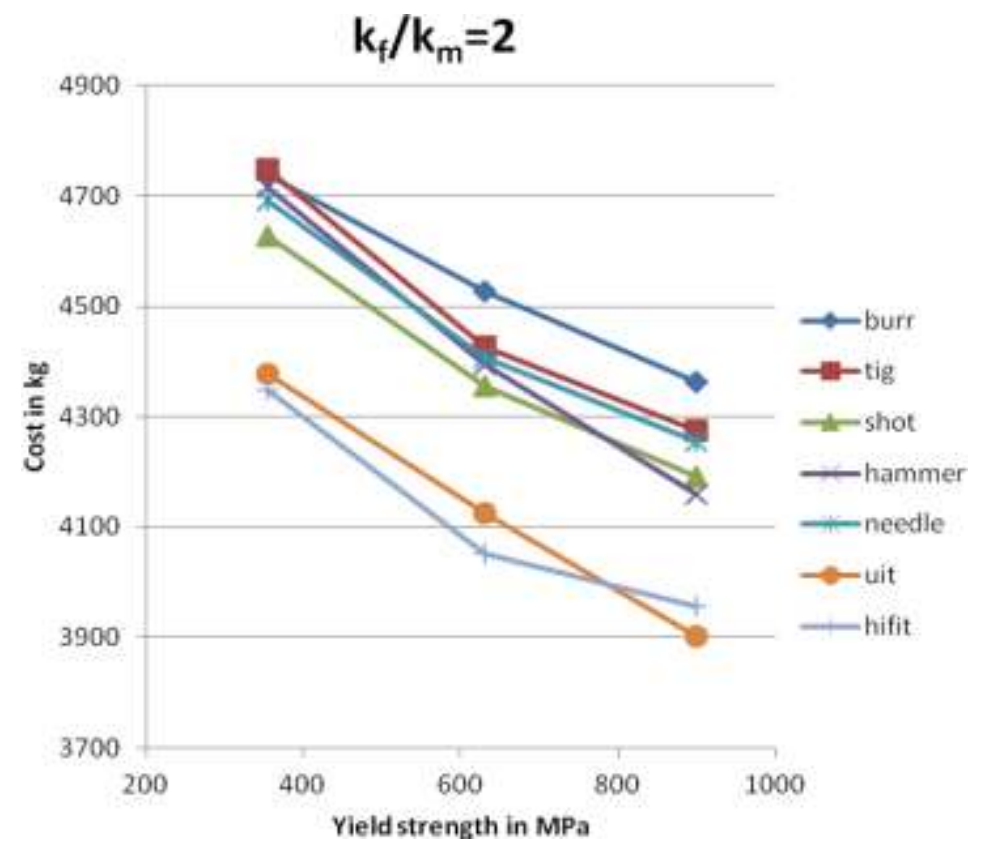

Figure 3 - The optimum costs in the function of the yield stress for $k_{\mathrm{f}} / k_{\mathrm{m}}=2$

Table 5 - Cost savings with different PWT techniques in \% comparing to the as welded structure.

\begin{tabular}{c|c|c}
\hline Method & $\begin{array}{c}\text { Cost saving for } \\
\text { mild steel }\end{array}$ & $\begin{array}{c}\text { Cost saving for } \\
\text { high strength steel }\end{array}$ \\
\hline Burr grinding & 12.5 & 25.4 \\
\hline TIG dressing & 12.8 & 26.3 \\
\hline Shot peening & 16.7 & 30.0 \\
\hline Hammer peening & 14.5 & 31.1 \\
\hline Needle peening & 15.0 & 26.9 \\
\hline UIT & 22.8 & 41.0 \\
\hline HiFIT & 24.1 & 39.1
\end{tabular}

\section{Conclusion}

This research is a continuation of our previous research considering the new PWT technologies, appeared recently, and using more stable parameters for the specific technologies. The presented results show the possible cost reduction due to PWT. Optimum design is suitable for this task, since the additional cost of PWT can be included in the cost function and the improved fatigue stress range can be considered in the fatigue strength constraint. Thus, the aim was to illustrate this saving by means of a simple numerical example of a welded I-beam.

In this case, the transverse fillet welds used for vertical stiffeners decrease the fatigue stress range, and thus the effect of PWT can be illustrated minimizing the cost function, which contains also the additional cost of PWT and the increased fatigue stress range can be included in the fatigue stress constraint.

The lower value is for the mild steel, and the higher value for the high-strength steel as shown in Table 5 and also the percentage saving. In Table 6, the optimum sizes of the welded I-beam with discrete values are listed. We did not consider that the higher-strength steels are more expensive, but the comparison is made to the as welded structure, with the same steel grade.

Broad ranges of improvement values and speed values of a PWT process are available in the literature, we have made a search on the scientific publications of this topic, and we have selected so called "main values", and their order may change using other values.

Cost savings show that using PWTs one can reduce the cost of the structure, even if introducing an additional treatment process to the production line. This reduction can be reached in the design phase only, combining the design and manufacturing aspects with economy issues. 
Table 6 - Results of optimization

\begin{tabular}{|c|c|c|c|c|c|c|}
\hline Yield strength & $k_{f} / k_{m}[\mathrm{~kg} / \mathrm{min}]$ & $h$ & $t_{w}$ & $b$ & $t_{f}$ & $K / k_{m}[\mathrm{~kg}]$ \\
\hline \multicolumn{7}{|c|}{ As welded } \\
\hline & 0 & 1300 & 10 & 300 & 15 & 2187 \\
\hline & 1 & 1230 & 10 & 310 & 16 & 3802 \\
\hline & 2 & 1230 & 10 & 310 & 16 & 5399 \\
\hline \multicolumn{7}{|c|}{ Burr Grinding } \\
\hline \multirow{2}{*}{$\leq 355 \mathrm{MPa}$} & 1 & 1040 & 10 & 290 & 16 & 3377 \\
\hline & 2 & 1040 & 9 & 300 & 16 & 4738 \\
\hline$>355 \mathrm{MPa}$ & 1 & 1010 & 10 & 250 & 17 & 3207 \\
\hline$<900 \mathrm{MPa}$ & 2 & 1010 & 10 & 210 & 20 & 4527 \\
\hline \multirow[b]{2}{*}{$\geq 900 \mathrm{MPa}$} & 1 & 890 & 9 & 240 & 20 & 3031 \\
\hline & 2 & 900 & 9 & 250 & 19 & 4363 \\
\hline \multicolumn{7}{|c|}{ TIG-Dressing } \\
\hline \multirow{2}{*}{$\leq 355 \mathrm{MPa}$} & 1 & 1040 & 10 & 290 & 16 & 3370 \\
\hline & 2 & 1080 & 10 & 240 & 18 & 4749 \\
\hline$>355 \mathrm{MPa}$ & 1 & 880 & 9 & 270 & 20 & 3162 \\
\hline$<900 \mathrm{MPa}$ & 2 & 870 & 8 & 280 & 20 & 4428 \\
\hline \multirow{2}{*}{$\geq 900 \mathrm{MPa}$} & 1 & 950 & 10 & 240 & 17 & 3052 \\
\hline & 2 & 930 & 9 & 220 & 20 & 4274 \\
\hline \multicolumn{7}{|c|}{ Shot Peening } \\
\hline \multirow{2}{*}{$\leq 355 \mathrm{MPa}$} & 1 & 970 & 9 & 260 & 20 & 3241 \\
\hline & 2 & 950 & 9 & 270 & 20 & 4627 \\
\hline$>355 \mathrm{MPa}$ & 1 & 990 & 10 & 240 & 17 & 3104 \\
\hline$<900 \mathrm{MPa}$ & 2 & 920 & 9 & 240 & 20 & 4356 \\
\hline \multirow{2}{*}{$\geq 900 \mathrm{MPa}$} & 1 & 860 & 9 & 270 & 17 & 2925 \\
\hline & 2 & 860 & 9 & 270 & 17 & 4192 \\
\hline \multicolumn{7}{|c|}{ Hammer Peening } \\
\hline \multirow{2}{*}{$\leq 355 \mathrm{MPa}$} & 1 & 1020 & 9 & 290 & 17 & 3298 \\
\hline & 2 & 1020 & 9 & 290 & 17 & 4717 \\
\hline$>355 \mathrm{MPa}$ & 1 & 880 & 9 & 260 & 19 & 3056 \\
\hline$<900 \mathrm{MPa}$ & 2 & 880 & 9 & 260 & 20 & 4395 \\
\hline \multirow{2}{*}{$\geq 900 \mathrm{MPa}$} & 1 & 850 & 9 & 290 & 15 & 2900 \\
\hline & 2 & 930 & 10 & 200 & 18 & 4160 \\
\hline \multicolumn{7}{|c|}{ Needle Peening } \\
\hline \multirow{2}{*}{$\leq 355 \mathrm{MPa}$} & 1 & 1020 & 9 & 310 & 16 & 3305 \\
\hline & 2 & 1020 & 9 & 290 & 17 & 4691 \\
\hline$>355 \mathrm{MPa}$ & 1 & 1050 & 10 & 280 & 14 & 3201 \\
\hline$<900 \mathrm{MPa}$ & 2 & 870 & 8 & 280 & 20 & 4408 \\
\hline \multirow{2}{*}{$\geq 900 \mathrm{MPa}$} & 1 & 950 & 10 & 240 & 17 & 3040 \\
\hline & 2 & 900 & 9 & 230 & 20 & 4255 \\
\hline \multirow{3}{*}{$\leq 355 \mathrm{MPa}$} & & UIT & & & & \\
\hline & 1 & 1010 & 10 & 210 & 19 & 3097 \\
\hline & 2 & 830 & 8 & 290 & 20 & 4377 \\
\hline$>355 \mathrm{MPa}$ & 1 & 930 & 10 & 200 & 18 & 2861 \\
\hline$<900 \mathrm{MPa}$ & 2 & 880 & 10 & 220 & 18 & 4125 \\
\hline \multirow{2}{*}{$\geq 900 \mathrm{MPa}$} & 1 & 890 & 10 & 210 & 15 & 2696 \\
\hline & 2 & 770 & 9 & 280 & 15 & 3903 \\
\hline \multicolumn{7}{|c|}{ HiFIT } \\
\hline \multirow{2}{*}{$\leq 355 \mathrm{MPa}$} & 1 & 950 & 10 & 240 & 17 & 3038 \\
\hline & 2 & 950 & 10 & 240 & 17 & 4349 \\
\hline$>355 \mathrm{MPa}$ & 1 & 860 & 9 & 210 & 20 & 2800 \\
\hline$<900 \mathrm{MPa}$ & 2 & 840 & 9 & 220 & 20 & 4051 \\
\hline
\end{tabular}




\begin{tabular}{lllllll}
\hline \multirow{2}{*}{$\geq 900 \mathrm{MPa}$} & 1 & 880 & 10 & 210 & 16 & 2733 \\
& 2 & 790 & 9 & 280 & 15 & 3955 \\
\hline
\end{tabular}

\section{Acknowledgement}

The research was supported by the TÁMOP 4.2.4.A/2-11-1-2012-0001 priority project entitled 'National Excellence Program - Development and operation of domestic personnel support system for students and researchers, implemented within the framework of a convergence program, supported by the European Union, co-financed by the European Social Fund. The research was supported also by the Hungarian Scientific Research Fund OTKA T 109860 project and was partially carried out in the framework of the Center of Excellence of Innovative Engineering Design and Technologies at the University of Miskolc. Thanks for the Erasmus exchange program between universities of Miskolc and Magdeburg, within Mr. Pahlke could join to this project.

\section{References}

[1] Hobbacher A. et al.: IIW Recommendations for fatigue design of welded joints and components, International Institute of Welding (IIW), Doc. XIII-2151r3-07_XV-1254r3-07_IIW-rec-26, 2007, 148 p.

[2] Haagensen P., Maddox S.: IIW Recommendations on Post Weld Improvement of Steel and Aluminium Structures, International Institute of Welding (IIW), Doc. XIII-2200r3-07, 2009.

[3] Pederson M., Mouritsen O., Hansen M., Andersen J. \& Wenderby J.: Comparison of Post Weld Treatment of High Strength Steel Welded Joints in Medium Cycle Fatigue, International Institute of Welding (IIW), Doc. XIII-2272-09, 2009.

[4] Kirkhope K.J., Bell R., Caron L., Basu R.I. \& Ma K.-T.: Weld detail fatigue life improvement techniques. Part 1: review, Marine Structures 12;1999:447-474.

[5] Kirkhope K.J., Bell R., Caron L., Basu R.I. \& Ma K.-T.: Weld detail fatigue life improvement techniques.Part 2: application to ship structures, In: Marine Structures 12;1999:477-496.

[6] Gerster P.: Verlängerung der Lebensdauer v. Schweißkonstruktionen durch die UIT-Technologie, (Applied Ultrasonics Europe, Ehingen), Vortrag Duisburger Schweißtage (2008).

[7] Miki C., Anami K., Tani H. \& Sugimoto I.: Methods for fatigue strength improvement by weld toe treatment, Welding International, 13(10)1999:795-803.

[8] Wang Ting, Wang Dongpo, Huo Lixing \& Zhang Yufeng: Discussion on fatigue design of welded joints enhanced by ultrasonic peening treatment (UPT), International Journal of Fatigue, 31;2009:644-650.

[9] Dokumentation D 761, "REFRESH - Extension of the fatigue life of existing and new welded steel structures", Verlag und Vertriebsgesellschaft mbH, Düsseldorf (2010).

[10] "Pfeiffer HiFIT Post Weld Treatment" product brochure (2009).

[11] Schaumann, P., Keindorf C.: Enhancing Fatigue Strength by Ultrasonic Impact Treatment for Welded Joints of Offshore Structures, Third International Conference on Steel and Composite Structures (ICSCS07), Manchester, UK (2007).

[12] Weich I., Ummenhofer T.: Effects of High-Frequency Peening Methods on the Surface Layers and the Fatigue Strength of Welded Details, Materials and Manufacturing Processes, 26(2)2011:288-293.

[13] Hasegawa M., Suzuki H. \& Miura K.: Effect of strong shot peening cleaning and hot galvanizing on fatigue strength of steel welded joint, Welding International, 23(5)2009:360-368.

[14] Walbridge S., Nussbaumer A.: A probabilistic assessment of the effect of post-weld treatment on the fatigue performance of tubular truss bridges, Engineering Structures 30(2008):247-257.

[15] Weich I., Ummenhofer T., Nitschke-Pagel Th., Dilger K. \& Eslami H.: Fatigue behaviour of welded high-strength steels after high frequency mechanical post-weld treatments, Doc. IIW-2001-09 (ex-doc. XIII-2154r1-07), Welding in the World, 53(11/12)2009:322-332.

[16] Weich I.: Edge layer condition and fatigue strength of welds improved by mechanical post-weld treatment, Welding in the World 55(2)2011:3-12.

[17] Lopez Martinez L., Blom A.F., Trogen H. \& Dahle T.: Fatigue behaviour of steels with strength levels between 350 and $900 \mathrm{MPa}$ influence of post weld treatment under spectrum loading, Proceedings of the North European Engineering and Science Conference, (NESCO): "Welded High-Strength Steel Structures", Stockholm, 1997; Edited by A.F. Blom, EMAS Publishing, London

[18] Zaczek Z.: Increasing the fatigue strength of welded joints, Welding International, 5(12)1991:990-994.

[19] Tilly G.P., Jackson P.A., Maddox S.J. \& Henderson R.: Fatigue strengthening of welds in light rail structures, in: Proceedings of the Institution of Civil Engineers Bridge Engineering 163 September 2010 Issue BE3 pages 147-152. 
[20] Woodley C.C.: Practical applications of weld toe grinding. In Improving the Fatigue Strength of Welded Joints. The Welding Institute, Abington, Cambridge, UK, 1983:19-22.

[21] Braid J.E.M., Bell R. \& Militaru D.V.: Fatigue life of as-welded, repaired, and hammer-peened joints in high-strength structural steel. Welding in the World, 39(5)1997:248-261.

[22] Janosch J.J., Koneczny H., Debiez S., Statnikov E.C., Troufiakov V.J. \& Mikhee P.P.: Improvement of fatigue strength in welded joints (in HSS and aluminium alloys) by ultrasonic hammer peening. Welding in the World, 37(2)1996:72-83.

[23] Horn A.A., Huther I. \& Lieurade H.P.: Fatigue behaviour of T-joints improved by TIG dressing. Welding in the World, 41(4)1998:273-280.

[24] Hasegawa M., Ohta K. \& Suzuki H.: Improvement of fatigue strength of SM490A welded joints by high-hardness/high-specific gravity shot peening, Welding International, 18(3)2004:181-188.

[25] Roy S., Fisher J.W.: Modified AASHTO design S - N curves for post-weld treated welded details, Bridge Structures: Assessment, Design and Construction, 2(4)2006:207-222.

[26] Maddox S.J.: Improving the fatigue lives of fillet welds by shot peening. Proceedings IABSE Colloquium on Fatigue of Steel and Concrete Structures. Lausanne, Switzerland, 1982.

[27] Jármai K., Farkas J. \& Haagensen P.J.: Effect of post-welding treatment on the optimum fatigue design of welded I-beams. Welding in the World, 44(2)2000:56-59.

[28] Roy S., Fisher J.W.: Improving Fatigue Strength of Welded Joints by Ultrasonic Impact Treatment, IABSE Symposium Report, IABSE Symposium, Shanghai 2004: Metropolitan Habitats and Infrastructure, pp. 206-211(6)

[29] Yildirim H.C., Marquis G.B.: Fatigue strength improvement factors for high strength steel welded joints treated by high frequency mechanical impact. International Journal of Fatigue, 41;2012 (accepted for publication) http://dx.doi.org/10.1016/j.ijfatigue.2012.05.002

[30] Tai M., Miki C.: Improvement effects of fatigue strength by burr grinding and hammer peening under variable amplitude loading. 56(8)2012:109-117.

[31] Vilhauer B., Bennett C.R., Matamoros A.B. \& Rolfe S.T.: Fatigue behavior of welded coverplates treated with Ultrasonic Impact Treatment and bolting. Engineering Structures 34;2012:163-172.

[32] Yekta, R.T., Ghahremani, K. \& Walbridge, S.: Effect of Quality Control Parameter Variations on the Fatigue Performance of Ultrasonic Impact Treated Welds, International Journal of Fatigue (2013), doi: http://dx.doi.org/10.1016/j.ijfatigue.2013.06.023

[33] Marquis G.B., Mikkola E., Yildirim H.C., Barsoum Z.: Fatigue strength improvement of steel structures by high-frequency mechanical impact: proposed fatigue assessment guidelines. Welding in the World, online first, DOI 10.1007/s40194-013-0075-x

[34] Eurocode 3: Design of steel structures - Part 1-9: Fatigue, EN 1993-1-9:2005. 